\title{
Lipase Activity during Endodormancy in Leaf Buds of Apple
}

\author{
Dehua Liu' and Helen A. Norman ${ }^{2}$ \\ Agricultural Research Service, Beltsville, MD 20705
}

\author{
Gary W. Stutte \\ Department of Horticulture, University of Maryland, College Park MD 20742 \\ Miklos Faust $^{1}$ \\ Agricultural Research Service, Beltsville, MD 20705
}

\begin{abstract}
Lipase activity was studied during endodormancy in low-chilling-requiring 'Anna' and high-chilling-requiring 'Northern Spy' apples (Malus domestica Borkh.). Lipase activity greatly increased in bud axes when the chilling requirement of buds was almost satisfied regardless of the absolute chilling needed. Lipase activity greatly increased in 'Anna' after 400 chill units (CU) and in 'Northern Spy' after $2600 \mathrm{CU}$. This corresponded with an increase in budbreak at 22 to $24 \mathrm{C}$. The increase in lipase activity also coincided with the release of water in buds from the bound to the free form. We propose that lipase(s) activity is an integral part of breaking dormancy and that lipase participates in causing changes in membrane lipid composition that coincides with releasing water into the free form.
\end{abstract}

Temperate-zone fruit trees, including apple, enter into a dormant period in late fall (Faust, 1989). The removal of dormancy requires a certain amount of "chilling" between 2 and 9C before the plants can resume growth [see reviews by Saure (1985) and Faust (1989)]. Although chilling requirements have been established for most cultivars, little is known about the physiological and biochemical events that mark the end of the chilling requirement (Faust, 1989).

Lang (1987) and Lang et al. (1985) proposed a unified terminology for dormancy. They distinguished states of para-, endo-, and ecodormancy. Endodormancy is "deep" dormancy and is equal to the "rest" period of winter dormancy designated by Williams et al. (1979). Endodormancy is regulated by factors within the dormant organ of the tree, whereas the other dormancy states are regulated either by influences located within the tree, but outside of the dormant organ, or by environmental factors. Several authors (Doorenbos, 1953; Jacobs et al., 1981) have come to the conclusion that, within a tree, dormancy is limited to buds. Magnetic resonance images of apple buds and stem tissues, taken during dormancy, indicated that water is bound to macromolecules in the dormant bud (Faust et al., 1991), but it is in the free form in fully chilled buds, which marks the end of endodormancy. In contrast, water is in the free form in the cambium and in the xylem even during the period in which the buds are endodormant (Faust et al., 1991). Using the form of water as an indication of dormancy, the same conclusion can be drawn as by Doorenbos (1953) and Jacobs et al. (1981)that the bud is the only structure within the tree exhibiting endodormancy. The work of Bewley and Black (1982) and Davidowicz-Grzegorzewska (1989) suggests that the dormancybreaking mechanism in seeds maybe limited to very few cells in the meristem. However, no comparable work exists for buds. In seeds it is believed that specific metabolic events take place during low-temperature accumulation that have a definite role in breaking dormancy. Mobilization of storage proteins and lipids constitute the essential step in removal of apple seed dor-

Received for publication 17 Oct. 1990. The cost of publishing this paper was defrayed in part by the payment of page charges. Under postal regulations, this paper therefore must be hereby marked advertisement solely to indicate this fact.

'Fruit Laboratory.

${ }^{2}$ Weed Science Laboratory. mancy involving activation of specific lipases (Lewak, 1984, 1985; Zarska-Maciejewska and Lewak, 1976, 1983). There are several reports on biochemical changes occurring during winter and during budbreak in apple buds (Wang et al., 1986). These studies were done with whole buds and not with the embryonic axis of the bud where release of dormancy is likely to occur. Chilling was not recorded concomitantly; thus, the end of the chilling requirement could not be determined.

Magnetic resonance imaging (Faust et al., 1991) of water in buds showed that there must be a change in cellular organization as a result of chilling, possibly in membranes, that liberates water from the bound to the free form. The study reported here was conducted to determine the possible correlation between chilling and lipase activity during the chilling-mediated process for releasing dormancy of apple buds.

\section{Materials and Methods}

Determining budbreak. Leaf buds of 'Anna', a low-chillingrequiring cultivar, and 'Northern Spy', a high-chilling-requiring cultivar, were used. One-year-old shoots were collected in Oct. 1989. Shoots were defoliated, packed in moistened peat, wrapped in plastic, and stored in a room maintained at $4 \mathrm{C}$, according to methods of Steffens and Stutte (1989). Each hour at 4C was considered as $1 \mathrm{CU}$. Samples were taken from cold storage after specified CU accumulation. For determining budbreak, 20 shoots were prepared by recutting the base of the shoots. Ten shoots were dipped into a solution containing $250 \mu \mathrm{M}$ thidiazuron (TDZ), $3.75 \%$ dimethylsulfoxide (DMSO), and $0.75 \%$ Tween 20 . Ten shoots remained untreated. TDZ was used to distinguish the physiological state of dormant buds by its ability to force budbreak of ecodormant or paradormant but not endodormant buds (Steffens and Stutte, 1989). Its use in this series of experiments was intended to mark a possible physiological change in the buds that is not perceptible in any other way. Both groups of shoots were placed in glass jars containing distilled water at 22 to $24 \mathrm{C}$ for 2 to 3 weeks to observe budbreak. The basal ends of shoots were recut and the water in the jars was changed at weekly intervals. Budbreak was recorded at those same times.

Determining lipase activity. For the study, ${ }^{14} \mathrm{C}$-labelled triglyceride substrate was prepared by isolation of triglyceride from

Abbreviations: CU, chill units; DMSO, dimethylsulfoxide; TDZ, thidiazuron. 
leaves of Arabidopsis thaliana (L) Heynh incubated with ${ }^{14} \mathrm{C}$ labelled lauric acid [26 $\mathrm{mCi} / \mathrm{mmol}(1 \mathrm{Ci}=37 \mathrm{GBg})]$ (Amersham, Arlington Heights, Ill.). Bud axes, taken from buds immediately before the experiment started, were homogenized in $100 \mathrm{~mm}$ PIPES-KOH (pH 6.5) buffer containing 5 mm dithiothreitol and $1 \mathrm{mM} \mathrm{CaCl}_{2}$ (Moreau, 1985); The reaction was started by sonification with $50 \mathrm{nmol}{ }^{14} \mathrm{C}$-labelled triglyceride dispersed in $5 \mathrm{ml}$ homogenization buffer. After $30 \mathrm{~min}$ incubation at $25 \mathrm{C}$ with continuous shaking, the lipase catalyzed reaction was stopped by adding $100 \mathrm{~mm}$ EDTA and $5 \mathrm{ml}$ methanol. Lipids were then extracted by a modification of the procedure of Bligh and Dyer (1959). Lipid extracts were fractioned into neutral lipid, galactolipid, and phospholipid classes using silica Sep-Pak cartridges (Water Assoc., Milford, Mass.) (Norman and St. John, 1987). The neutral lipids were further separated by thin-layer chromatography (TLC) on silica gel H (E. Merck, Darmstadt, Germany) using 70 petroleum ether : 30 ethyl ether : 1 acetic acid (by volume) as the developing solvent (Matthew and $\mathrm{Mu}-$ kherjee, 1988). After removal of solvents under $\mathrm{N}_{2}$ for $5 \mathrm{~min}$, lipid bands were located by exposing the plates briefly to iodine vapor. Sample bands were identified by cochromatography of fatty acid, diglyceride, and triglyceride standards. The bands were immediately scraped off the plate, transferred to scintillation vials, and radioactivity was determined using a Beckman LS 1801 liquid scintillation counter (Beckman Instrument, Fullerton, Calif.). Aliquots of the total lipid fractions were also assayed. Counting efficiency for ${ }^{14} \mathrm{C}$ was $85 \%$. Lipase activity was expressed as nanomole of triglyceride hydrolyzed per gram (fresh weight) of bud axes. Each assay was carried out in triplicate and results are expressed as means \pm SE.

\section{Results}

Buds of 'Anna' required $600 \mathrm{CU}$ for $90 \%$ budbreak and 'Northern Spy' required 3000 CU for $80 \%$ budbreak (Figs. 1 A and B). 'Anna' and 'Northern Spy' were partially chilled with $200 \mathrm{CU}$ and $2000 \mathrm{CU}$, resulting in $12.9 \%$ to $15.0 \%$ and $21.3 \%$ to $23.2 \%$ budbreak, respectively (Table 1 ). Increasing the time buds were kept at 22 to $24 \mathrm{C}$ to 24 days, in the case of 'Anna', and to 48 days, in the case of 'Northern Spy', did not increase the percentage of budbreak.

Budbreak in 'Anna' started after the buds were exposed to $200 \mathrm{CU}$, increased somewhat at $400 \mathrm{CU}$, and was greatest after $600 \mathrm{CU}(86 \%)$ (Fig. 1A). TDZ had no effect on budbreak of unchilled 'Anna' buds, but more than doubled budbreak (12.9\% to $28.3 \%$ ) of buds that received $200 \mathrm{CU}$. The effect of TDZ on budbreak at $200 \mathrm{CU}$ was close to that of control buds that received $400 \mathrm{CU}$. TDZ had no significant effect on budbreak at $400 \mathrm{CU}$, when buds were almost chilled, or at $600 \mathrm{CU}$, when the buds were fully chilled (Fig. 1A).

Budbreak for 'Northern Spy' started at $2000 \mathrm{CU}$ and was higher at $2600 \mathrm{CU}$ (Fig. 1B). TDZ also increased budbreak in 'Northern Spy' at $2000 \mathrm{CU}$, from $20.2 \%$ to $59.1 \%$, which was very close to that obtained at $2600 \mathrm{CU}$ without TDZ (Fig. 1B).

A slightly higher lipase activity was observed in 'Anna' buds that received 200 rather than $0 \mathrm{CU}$ (Fig. 2A). However, lipase activity increased 6-fold in buds that received $400 \mathrm{CU}$. Lipase values at 400 and $600 \mathrm{CU}$ were similar. Lipase activity in 'Northern Spy' buds was low but increased gradually with chilling to $2000 \mathrm{CU}$. Lipase activity increased significantly from 2000 to $2600 \mathrm{CU}$ and appeared to peak, dropping significantly at $3000 \mathrm{CU}$ (Fig. 2b). A similar trend was observed in lipase activity in buds of 'Anna', in that peak values appeared to occur at full chilling accumulation (400 CU) and decreased with more
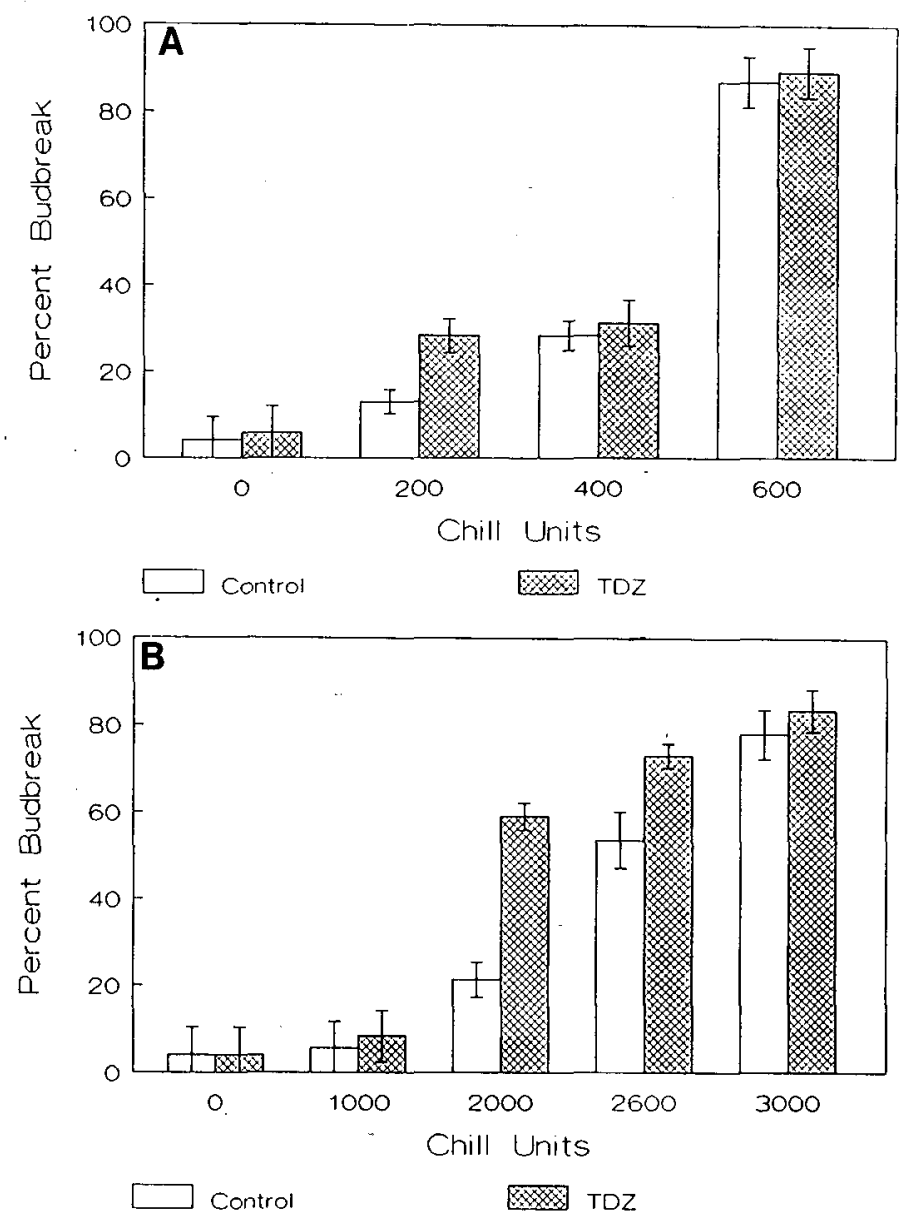

Fig. 1. Effect of CU accumulation and TDZ treatment on budbreak of (A) 'Anna' and (B) 'Northern Spy' apple leaf buds.

Table 1. Effect of length of time at $22 \mathrm{C}$ on budbreak of partially chilled leaf buds of 'Anna' and 'Northern Spy' apples.

\begin{tabular}{lcc}
\hline \hline \multirow{2}{*}{$\begin{array}{l}\text { Time } \\
\text { at } 22 \mathrm{C}\end{array}$} & \multicolumn{2}{c}{ Cultivar } \\
\cline { 2 - 3 } (days) & Anna & Northern Spy \\
\cline { 2 - 3 } & \multicolumn{3}{c}{ Budbreak (\%) } \\
\hline 6 & $9.5 \pm 6$ & $13.1 \pm 2.8$ \\
12 & $12.9 \pm 2.8$ & $21.3 \pm 4.1$ \\
18 & $15.0 \pm 3.6$ & $23.2 \pm 5.5$ \\
24 & $17.1 \pm 4.6$ & $24.2 \pm 5.0$ \\
48 & -- & $20.7 \pm 4.1$ \\
\hline
\end{tabular}

z'Anna' buds were chilled to $200 \mathrm{CU}$; 'Northern Spy' buds were chilled to $2000 \mathrm{CU}$.

chilling accumulation, although the difference was not significant statistically.

\section{Discussion}

The amount of low temperature required to overcome endodormancy of buds is referred to as the chilling requirement (Lang et al., 1985; Powell, 1986). Generally, it is agreed that the chilling requirement is satisfied when $50 \%$ of the buds are opened after 10 to 14 days at 21C (Mielke and Dennis, 1975; Steffens and Stutte, 1989). Our data show that $50 \%$ budbreak occurred in 'Anna' soon after $400 \mathrm{CU}$, and $600 \mathrm{CU}$ was more than adequate to release dormancy. In 'Northern Spy', satisfying chilling requirement occurred at $\approx 2600$ CU.

TDZ is a cytokinin-like compound that is effective in forcing 

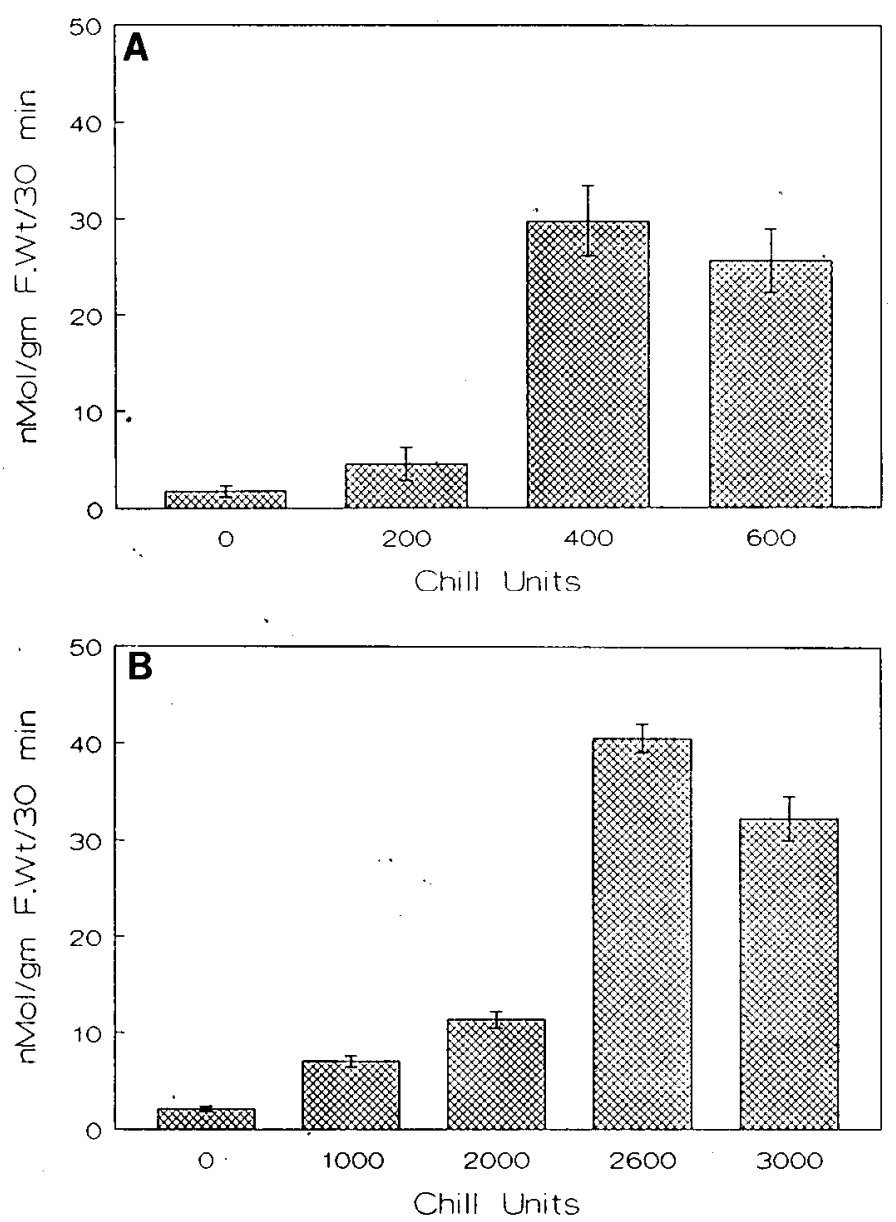

Fig. 2. Effect of CU accumulation on lipase activity in (A) 'Anna' and (B) 'Northern Spy' apple buds.

growth in partially chilled apple buds (Steffens and Stutte, 1989; Wang et al., 1986; Yip and Yang, 1986). TDZ is thought to be more effective in overcoming paradormancy than in providing a stimulus that negates endodormancy (Steffens and Stutte, 1989). Paradormancy is the stage when dormancy is controlled by factors outside of the bud; i.e., environmental factors during early spring and apical dominance during summer (Lang, 1987). Work of Steffens and Stutte (1989) showed that TDZ could be used as an exogenous factor indicating the end of endodormancy and the transition of buds into paradormaney. Our results show that TDZ increased budbreak of 'Anna' after $400 \mathrm{CU}$ and 'Northern Spy' after $2000 \mathrm{CU}$, which indicates that the two cultivars were very close to having their chilling requirement satisfied. Concomitantly, lipase activity peaked in each cultivar at its respective critical CU accumulation for breaking dormancy.

It is not certain how chilling overcomes endodormancy (Powell, 1986). There is some evidence that metabolic events take place in dormant apple embryos that result in removal of dormancy (Nguyen et al., 1984; Zarska-Maciejewska and Lewak, 1976, 1983). Degradation of storage lipids in apple seeds was preceded by an increased acid lipase activity, and the degradation of lipid bodies was totally dependent on low-temperature treatment, which, in turn, was necessary to remove dormancy (Davidowicz-Grzegorzewska, 1989). Our results indicate a close relationship between lipase activity and end of dormancy. However, we were unable to determine whether this relationship is correlative or causative. Interpretation of our finding is made difficult by the relative scarcity of knowledge regarding plant lipases in general, compared to mammalian systems (Huang, 1987). While it is known that lipolytic enzymes catalyze initial steps in mobilization of storage triglyceride and that turnover of membrane lipids in various tissues may depend on fatty acyl hydrolases, regulatory factors in enzyme activity are not clearly elucidated (Huang, 1987). True lipases (i.e., active on triglycerides) previously have been studied in seeds, with only occasional reports in other tissues or organs.

Research with magnetic resonance imaging (MRI) shows that an increase in free water in apple buds became observable at 400 and 3000 CUs of chilling for 'Anna' and 'Northern Spy', respectively. At these CUs, only a trace amount of free water was visible on MRI, but a large amount of free water was visible at the next level of chilling for each cultivar (600 and 4000 CUs) (Faust et al., 1991). Bound water in tissues may be associated with protein and/or cell wall complexes. During endodormancy, water apparently is in a bound form and needs to be liberated into free form before dormancy can be broken. Faust et al. (1991) proposed that endodormaney, when the dormancy is influenced by factors within the cell, is, in fact, a period when water is in a bound form. Lipase activity increased markedly at about the time when free water started to show up in the buds. This change suggests that the hydrolysis of lipids has an effect on freeing water and this, in turn, allows, or perhaps contributes to, the breaking of dormancy. Notably, lipase activity in both cultivars coincided with the end of endodormancy, yet there was more than a 6.5 -fold difference between the two cultivars in CUs required to break dormancy. The difference in cellular organization or in genetic expression that distinguishes a low- and a high-chilling cultivar is not known, but it appears that, with the exception of timing, the mechanism is the same.

\section{Literature Cited}

Bewley, J.D. and M. Black. 1982. Physiology and biochemistry of seeds in relation to germination. 2:272-273. Springer Verlag, Berlin.

Bligh, E.G. and W.S. Dyer. 1959. A rapid method of total lipid extraction and purification. Can. J. Biochem. Biophys. 37:911-917.

Davidowicz-Grzegorzewska, A. 1989. Degradation of protein and lipid bodies during dormancy removal in apple seeds. J. Plant Physiol. 135:43-45.

Doorenbos, J. 1953. Review of literature on dormancy in buds of woody plants. Meded. Landbouwhogeschool, Wageningen 53:1-14.

Faust, M. 1989. Physiology of temperate zone fruit trees. Wiley, New York.

Faust, M., D. Liu, M.M. Millard, and G.W. Stutte. 1991. Bound versus free water in dormant apple buds-Theory for endodormancy. HortScience. (In press.)

Huang, A.H.C. 1987. Lipases, p. 91-118. In: P.K. Stumpf and E.E. Conn (eds.). The biochemistry of plants. Academic, New York.

Jacobs, G., P.J. Watermeyer, and D.K. Styrdom. 1981. Aspects of winter rest of apple trees. Crop Production 10:103-104.

Lang, G.A. 1987. Dormancy: A new universal terminology. HortScience 22:817-820.

Lang, G.A., J.D. Early, N.J. Arryave, R.L. Darnell, G.C. Martin, and G.W. Stutte. 1985. Toward reduced universal terminology. HortScience 29:809-811.

Lewak, S.T. 1984. Hormones in seed dormancy and germination, p. 95-144. In: S.S. Purchit (ed.). Hormonal regulation of plant growth and development. vol. 1.

Lewak, S.T. 1985. Seed dormancy-An adaptation to climatic conditions, p. 260-265. In: N.J. Kaur and J. Nielsen (eds.). Plant production in the North. Norvegian University Press, Oslo, Norway.

Matthew, J.H. and K.D. Mukherjee. 1988. Assay for triglycerol lipase 
by a rapid thin layer chromtographic technique. J. Lipid Res. 29:13971399.

Mielke, E.U. and F.G. Dennis. 1975. Hormonal control of flower bud dormancy in sour cherry (Prunus cerasus). III. Effects of leaves, defoliation and temperature on levels of abscisic acid in flower primordia. J. Amer. Soc. Hort. Sci. 103:446-449.

Moreau, R.A. 1985. Membrane-Degrading enzymes in the leaves of Solanum tuberosum. Photochemistry 24:411-414.

Nguyen, X.V., D. Come, S.T. Lewak, and P. Mazliak. 1984. Dormancy breaking and frost resistance induction in apple embryos as related to changes in reserve and polar lipids. Physiol. Plant. 62:566 570 .

Norman, H.A. and J.B St. John. 1987. Differential effects of a substituted pyridazinone, BASF 13-338, on pathways of monogalactosyldiacylglycerol synthesis in arabidopsis. Plant Physiol. 85:684688.

Powell, L.E. 1986. The chilling requirement of apple and its role in regulating time of flowering in spring in cold winter climates. Acts Hort. 179:129-133.
Saure, M.C. 1985. Dormancy release in deciduous fruit trees. Hort. Rev. 7:239-300.

Steffens, G.L. and G. W. Stutte. 1989. Thidiazuron substitution for chilling requirement in three apple cultivars. J. Plant Growth Regulat. 8:301-308.

Wang, S.Y., G.L. Steffens, and M. Faust. 1986. Breaking bud dormancy in apple with a plant bioregulator, thidiazuron, Photochemistry 25:311-317.

Williams, R.R., G.R. Edwards, and B.G. Coombe. 1979. Determination of the pattern of winter dormancy in lateral buds of apples. Ann. Bot. 44:575-581.

Yip, W.K. and S.F. Yang. 1986. Effect of thidiazuron, a cytokininactive urea derivative in cytokinin-dependent ethylene production systems. Plant Physiol. 80:515-519.

Zarska-Maciejewska, B. and S.T. Lewak. 1976. The role of lipases in the removal of dormancy in apple seeds. Planta 132: 177-181.

Zarska-Maciejewska, B. and S.T. Lewak. 1983. The role of proteolytic enzymes $\mathrm{m}$ the release from dormancy of apple seeds. Z. Pflanzenphysiol. 110:409-417. 